\title{
Factors associated with serum CA19-9 levels among healthy children: a cross-sectional study
}

\author{
Sayo Kawai ${ }^{{ }^{* \dagger}}$, Sueli M Oba-Shinjo ${ }^{2}$, Lucy S Ito ${ }^{3}$, Miyuki Uno², Suely K N Marie ${ }^{2}$ and Nobuyuki Hamajima ${ }^{1 \dagger}$
}

\begin{abstract}
Background: CA19-9 is a tumor marker mainly used for biliary tract, pancreas and colorectum. Since the marker applies usually for adults, the normal range of serum CA19-9 among children has been rarely reported. This is the first study reporting the distribution of serum CA19-9 levels among cancer-free children as well as their parents, taking into account the Lewis and secretor gene polymorphism and physical growth.

Methods: Study subjects were 972 apparently healthy Japanese Brazilians including 476 children aged from 1 to 19 years.

Results: The comparisons in five-year age groups demonstrated that the mean values of serum CA19-9 was lower in the boys than in the girls, and higher in younger age groups; $22.5 \mathrm{U} / \mathrm{ml}$ for $1-4$ year-old $(n=13), 17.4 \mathrm{U} / \mathrm{ml}$ for 5 9 year-old $(n=36), 15.5 \mathrm{U} / \mathrm{ml}$ for $10-14$ year-old $(n=96)$ and $10.2 \mathrm{U} / \mathrm{ml}$ for $15-19$ year-old $(n=74)$ in boys, and $25.3 \mathrm{U} /$ $\mathrm{ml}(n=11), 27.1 \mathrm{U} / \mathrm{ml}(\mathrm{n}=50), 17.7 \mathrm{U} / \mathrm{ml}(\mathrm{n}=105)$ and $13.5 \mathrm{U} / \mathrm{ml}(\mathrm{n}=59)$ in girls, respectively. The difference in those geometric means was statistically significant among four age groups ( $p=0.006$, ANOVA adjusted for sex). After Lewis and secretor genotypes, which are definitive factors of serum CA19-9, were taken into account, geometric mean of serum CA19-9 was associated with any of BMI $(p<0.001)$, height $(p<0.001)$ and weight $(p<0.001)$ among children excluding those with le/le genotype. The associations were still significant when age was adjusted.
\end{abstract}

Conclusions: Serum CA19-9 values were higher among children than among adults, and influenced by sex, height, weight, and BMl even after the adjustment for age as well as Le and Se genotypes.

Keywords: CA19-9, Healthy children, BMI, Lewis and secretor gene polymorphisms

\section{Background}

CA19-9 is a blood group antigen-related marker for cancer screening and a prognostic factor during treatment [1]. Currently, serum CA19-9 is regarded as the most sensitive and specific marker for the diagnosis and follow-up of pancreatic cancer. The sensitivity of the test to detect pancreatic cancer was $73.3 \%$ with $37 \mathrm{U} / \mathrm{ml}$ as the cutoff value, the specificity was $87.0 \%$, and the diagnostic accuracy was $60.3 \%$ [2]. CA19-9 is also raised in biliary tract [3], colorectum [1,4] and ovarian [5] malignancies. Increased levels of serum CA19-9 can also occur in hydronephrosis [6], and Hashimoto's Thyroiditis [7].

Since the assay for CA19-9 is using the antibody (1116-NS-19-9) that recognizes the carbohydrate

\footnotetext{
*Correspondence: ksayo@med.nagoya-u.ac.jp

${ }^{\dagger}$ Equal contributors

'Department of Preventive Medicine, Nagoya University Graduate School of Medicine, 65 Tsurumai-cho, Showa-ku, Nagoya, Japan

Full list of author information is available at the end of the article
}

structure sialylated Lewis a (sialyl-Le $\left.{ }^{\mathrm{a}}\right)$ structure [8], Lewis phenotype influences the CA19-9 concentration in serum. Two independent genes, Lewis gene (Le allele or $l e$ allele) and secretor gene ( $\mathrm{Se}$ allele or se allele), determine the Lewis phenotype [9]. In those with no enzyme activity genotype (le/le) of Lewis (Le) gene, serum CA19-9 values are negative $(<1.0 \mathrm{U} / \mathrm{ml})$, while no enzyme activity genotype (se/se) of secretor $(\mathrm{Se})$ gene is considered to have an association with high serum CA19-9 levels. In Japanese, the distinction of $l e$ from $L e$ was practically possible for genotyping T59G polymorphism (59T for Le and 59G for le). For Se gene, A385T (sej) and pseudogene (se5) were used for the detection of se alleles [10]. Our previous study showed the geometric mean of serum CA19-9 was significantly associated with current smoking among adults, independently of $L e$ and $S e$ genotypes [11]. However, since the tumor marker usually applies for adults, the abovementioned studies were all performed with adult subjects,

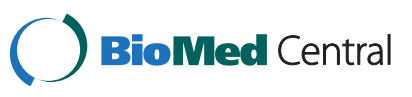


and there were few reports about the distribution of serum CA19-9 values of children.

To our knowledge, there were only three case-control studies on the distribution, so far. The first study was aimed to establish the reference values of tumor makers including CA19-9 for pediatric malignant diseases. They reported the distribution of serum CA19-9 concentration in 52 healthy children collected for a nutritional study aged 1 to 17 years [12]. Another study reported the mean values of serum CA19-9 among 30 pediatric outpatients without blood diseases as a control group compared with a 5-year-old patient of malignant lymphoma [13]. The other study reported that the mean values of serum CA19-9 among 27 healthy boys and girls whose mean age was 30.1 months, as a control group for 27 patients with unilateral ureteropelvic junction obstruction aged 0.5 to 98 months [14].

In order to make an accurate diagnosis or prognosis of disorders using serum CA19-9 for pediatric patients, it is important to know about the normal values of CA19-9 among children. In this study, we measured the serum CA19-9 values of children and adolescents aged less than 20 years among cancer-free Japanese-Brazilians, as well as those of their parents. The association between serum CA19-9 and candidate factors such as age, sex, weight, height, and body mass index (BMI, weight in kilogram divided by height squared in meter) were also examined.

\section{Methods}

\section{Study subjects}

The subjects of this study were apparently healthy family volunteers, who were enrolled for a study on Helicobacter pylori infection through Japanese-Brazilian societies in São Paulo in 2002 [15]. The family units were defined as husband, wife, and one or more children aged from 1 to 19 years and they all lived in the same household. Written informed consent was obtained from all the participants. In case of children, the parents signed the consent form instead of their children providing consent. The collection of lifestyle data and blood was conducted after the consent was obtained. Among the participated 1,037 Japanese Brazilians, 1,024 samples were available for CA19-9 measurement. Excluding the subjects lacking of one or more items of data under study, and one subject with more than $250 \mathrm{U} / \mathrm{ml}$ of serum CA19-9 who was on suspicion of carrying some diseases or disorders, 972 subjects (496 adults and 476 children) were applied to the present study. This study was approved by Ethics Committees of Nagoya University School of Medicine (approval number 1112).

\section{Quantitative analysis of serum CA19-9 and genotyping}

A 10-ml sample of venous blood was obtained from each participant. The blood samples were centrifuged and frozen at $-20^{\circ} \mathrm{C}$ according to an identical protocol, then they were transferred to Japan in 2002 and stored at $-80^{\circ} \mathrm{C}$ thereafter. The serum concentration of CA19-9 was measured by SRL Inc., Tokyo Japan, in 2009 with chemiluminescent enzyme immunoassay (CLEIA) (upper limit of normal range, $37 \mathrm{U} / \mathrm{ml}$ ). DNAs were extracted from the blood by a salting-out method and utilized for polymorphism analysis. The Le and Se gene polymorphisms were genotyped in 2009 by polymerase chain reaction with confronting twopair primers (PCR-CTPP) [16]. The detailed primer sets and PCR conditions were shown in our previous study [17].

\section{Statistical analysis}

Information about age, sex, smoking and alcohol drinking habit was self-reported and BMI was calculated from height and weight. Hardy-Weinberg equilibrium was tested for the $L e$ and $S e$ genotypes. Since the distribution of serum CA19-9 values followed lognormal, geometric means were tested by analysis of variance (ANOVA). When geometric means were calculated, the detectable limit $(1 \mathrm{U} / \mathrm{ml})$ was used for the below limit. Box and whisker plot in figures indicates lower adjacent value (the lowest datum still within 1.5 interquartile range of the lower quartile), 25th percentile (lower quartile), 50th percentile (median), 75th percentile (upper quartile), and upper adjacent value (the highest datum still within 1.5 interquartile range of upper quartile). All calculations were performed with the Stata 9 computer program (StataCorp, College Station, TX, USA).

\section{Results}

\section{Background characteristics and genotype frequencies}

Table 1 shows the characteristics of the subjects according to sex. The data indicated that the mean value of serum CA19-9 was higher in females than males. There were no smokers or alcohol drinkers among the 476 children aged less than 20 years. Among their parents, current smokers were $22.6 \%$ in males and $9.4 \%$ in females, and alcohol drinkers were $62.7 \%$ and $25.4 \%$, respectively.

Allele frequency of Le T59G polymorphism was $69.4 \%$ for $L e(59 \mathrm{~T})$ and $30.6 \%$ for le (59G), with 475 (48.9\%) subjects for Le/Le, 400 (41.1\%) for Le/le and 97 (10.0\%) for le/le. On Se A385T polymorphism and pseudogene, allele frequencies were $52.1 \%$ for $A(\mathrm{Se}), 42.2 \%$ for $T$ (sej) and $5.7 \%$ for pseudogene (se5), with 259 (26.7\%) for Sel $\mathrm{Se}, 495$ (50.9\%) for $\mathrm{Se} / \mathrm{se}$ and 218 (22.4\%) for se/se, where sej and se5 were categorized into one group as "se". There was only one subject with homozygous for se5 allele (se5/se5) in this dataset. The genotype frequencies for $L e$ and $\mathrm{Se}$ were in Hardy-Weinberg equilibrium $\left(\chi^{2}=0.89, p=0.34\right.$ and $\chi^{2}=0.40, p=0.53$, respectively). Table 2 shows $L e$ and Se genotype frequencies of the children and their parents. 
Table 1 Characteristics of study subjects

\begin{tabular}{|c|c|c|c|c|}
\hline \multirow[t]{3}{*}{ Characteristics } & \multicolumn{2}{|c|}{$\begin{array}{l}\text { Children aged less } \\
\text { than } 20 \text { years }\end{array}$} & \multicolumn{2}{|c|}{ Adults (Parents) } \\
\hline & Boys & Girls & Men & Women \\
\hline & $(\mathrm{N}=251)$ & $(\mathrm{N}=225)$ & $(\mathrm{N}=252)$ & $(\mathrm{N}=244)$ \\
\hline \multicolumn{5}{|l|}{ Age in years } \\
\hline Mean (Range) & $11.5(1-19)$ & $11.7(1-19)$ & $45.8(25-66)$ & $42.8(22-69)$ \\
\hline \multicolumn{5}{|l|}{ CA19-9 } \\
\hline Mean* $( \pm$ S.D. $)$ & $\begin{array}{c}14.8 \\
( \pm 19.4)\end{array}$ & $\begin{array}{c}19.1 \\
( \pm 21.4)\end{array}$ & $\begin{array}{c}9.5 \\
( \pm 9.3)\end{array}$ & $\begin{array}{c}11.9 \\
( \pm 11.9)\end{array}$ \\
\hline Range & $1-136$ & $1-128$ & $1-89.8$ & $1-87.2$ \\
\hline \multicolumn{5}{|l|}{ Height (cm) } \\
\hline Mean (Range) & $\begin{array}{c}147.7 \\
(72-185)\end{array}$ & $\begin{array}{c}143.8 \\
(60-172)\end{array}$ & $\begin{array}{c}167.9 \\
(150-190)\end{array}$ & $\begin{array}{c}156.0 \\
(140-173)\end{array}$ \\
\hline \multicolumn{5}{|l|}{ Weight (kg) } \\
\hline Mean (Range) & $\begin{array}{c}44.6 \\
(10-100)\end{array}$ & $\begin{array}{c}39.6 \\
(10-83)\end{array}$ & $\begin{array}{c}70.6 \\
(35-105)\end{array}$ & $\begin{array}{c}56.2 \\
(38-90)\end{array}$ \\
\hline \multicolumn{5}{|l|}{$\mathrm{BMI}\left(\mathrm{kg} / \mathrm{m}^{2}\right)$} \\
\hline Mean (Range) & $\begin{array}{c}19.4 \\
(6.1-35.0)\end{array}$ & $\begin{array}{c}18.6 \\
(5.9-33.3)\end{array}$ & $\begin{array}{c}25.0 \\
(15.6-36.3)\end{array}$ & $\begin{array}{c}23.1 \\
(16.9-37.8)\end{array}$ \\
\hline \multicolumn{5}{|l|}{ Smoking } \\
\hline Current smokers & 0 & 0 & $57(22.6 \%)$ & $23(9.4 \%)$ \\
\hline Non-current smokers & 0 & 0 & 195 (77.4\%) & $221(90.6 \%)$ \\
\hline \multicolumn{5}{|l|}{ Alcohol } \\
\hline Current drinkers & 0 & 0 & $158(62.7 \%)$ & $62(25.4 \%)$ \\
\hline Non-current drinkers & 0 & 0 & $94(37.3 \%)$ & $182(74.6 \%)$ \\
\hline
\end{tabular}

NOTE. BMI: body mass index. ${ }^{*}$ Arithmetic mean.

\section{Serum CA19-9 and ages of subjects}

The distribution of serum CA19-9 by age is shown in Figure 1. The comparison in five-year age groups demonstrated that the geometric mean of serum CA19-9 was higher in younger age groups; $22.5 \mathrm{U} / \mathrm{ml}$ for 1-4 year-old $(\mathrm{n}=13), 17.4 \mathrm{U} / \mathrm{ml}$ for 5-9 year-old $(\mathrm{n}=36), 15.5 \mathrm{U} / \mathrm{ml}$ for $10-14$ year-old $(\mathrm{n}=96)$ and 10.2 $\mathrm{U} / \mathrm{ml}$ for $15-19$ year-old $(\mathrm{n}=74)$ in boys, and $25.3 \mathrm{U} / \mathrm{ml}$ $(\mathrm{n}=11), 27.1 \mathrm{U} / \mathrm{ml}(\mathrm{n}=50), 17.7 \mathrm{U} / \mathrm{ml}(\mathrm{n}=105)$ and 13.5

Table 2 Genotype frequencies for Lewis and secretor polymorphisms

\begin{tabular}{lccc}
\hline Characteristics & Children & Parents & All subjects \\
\hline Lewis T59G & & & \\
Le/Le (TT) & $229(48.1 \%)$ & $246(49.6 \%)$ & $475(48.9 \%)$ \\
Le/le (TG) & $199(41.8 \%)$ & $201(40.5 \%)$ & $400(41.1 \%)$ \\
Le/le (GG) & $48(10.1 \%)$ & $49(9.9 \%)$ & $97(10.0 \%)$ \\
secretor A385T \& pseudogene* & & & \\
Se/Se & $121(25.4 \%)$ & $138(27.8 \%)$ & $259(26.7 \%)$ \\
Se/se & $251(52.7 \%)$ & $244(49.2 \%)$ & $495(50.9 \%)$ \\
se/se & $104(21.9 \%)$ & $114(23.0 \%)$ & $218(22.4 \%)$ \\
\hline${ }^{*}$ sej (385T) and se5 (pseudogene) are categorized into one group as “se”.
\end{tabular}

"sej (385T) and se5 (pseudogene) are categorized into one group as "se".

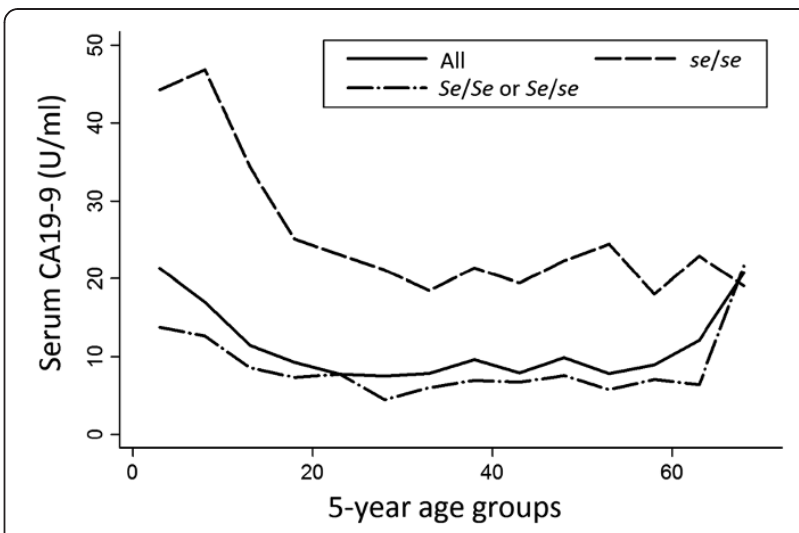

Figure 1 Geometric mean of serum CA19-9 for 5-year age groups according to Se genotype. Shift of the geometric mean of serum CA19-9 for each 5-year age groups according to Se genotype excluding those with le/le genotype.

$\mathrm{U} / \mathrm{ml}(\mathrm{n}=59)$ in girls, respectively. The difference in those geometric means was statistically significant among four age groups $(p=0.006$, ANOVA adjusted for sex). Regression analysis also indicated that age was significantly associated with logarithm of serum CA19-9 levels $(\beta,-0.022, p<0.001)$. This tendency was not observed among the parents ( $p=0.38$, ANOVA adjusted for sex). The significant association between serum CA19-9 and sex was also observed only among children $(p=0.004$ among the children and $p=0.29$ among the parents, ANOVA adjusted for four age groups).

Serum CA19-9 according to genotypes and generations Among the children aged less than 20 years, geometric mean for CA19-9 was $34.1 \mathrm{U} / \mathrm{ml}$ for Le/Le \& se/se, 32.6 $\mathrm{U} / \mathrm{ml}$ for Le/le \& se/se, $11.6 \mathrm{U} / \mathrm{ml}$ for Le/Le \& Se/se, 8.7 $\mathrm{U} / \mathrm{ml}$ for $\mathrm{Le} / \mathrm{Le} \& \mathrm{Se} / \mathrm{Se}, 8.3 \mathrm{U} / \mathrm{ml}$ for Le/le \& Se/se, 6.4

Table 3 Geometric means of serum CA19-9 (U/ml) for each genotype among the children and their parents

\begin{tabular}{lccc}
\hline Genotype & Children (N) & Parents (N) & $\boldsymbol{p}_{\text {-value }}$ \\
\hline Le/Le \& se/se & $34.1(37)$ & $20.9(57)$ & $<0.0001$ \\
Le/le \& se/se & $32.6(52)$ & $21.0(40)$ & 0.005 \\
Le/Le \& Se/se & $11.6(133)$ & $8.3(115)$ & $<0.0001$ \\
Le/Le \& Se/Se & $8.7(59)$ & $6.8(74)$ & 0.03 \\
Le/le \& Se/se & $8.3(97)$ & $6.3(109)$ & 0.001 \\
Le/le \& Se/Se & $6.4(50)$ & $5.5(52)$ & 0.36 \\
le/le \& se/se & $1^{\text {a }}(15)$ & $1^{\text {a }}(17)$ & $\mathrm{n} / \mathrm{a}$ \\
le/le \& Se/se & $1^{\mathrm{a}}(21)$ & $1.2(20)$ & 0.35 \\
le/le \& Se/Se & $1^{\mathrm{a}}(12)$ & $1.0(12)$ & 0.29 \\
Total & $9.3(476)$ & $7.1(496)$ & $<0.0001$ \\
\hline
\end{tabular}

${ }^{a}$ All subjects in the groups indicated below the detection limit $(1 \mathrm{U} / \mathrm{ml})$ ${ }^{\mathrm{b} C a l c u l a t e d}$ by ANOVA adjusted for sex. 
$\mathrm{U} / \mathrm{ml}$ for Le/le \& Se/Se, and below the detection limit $(1 \mathrm{U} / \mathrm{ml})$ for le/le \& se/se, le/le \& Se/se and le/le \& Se/Se. Among their parents, the mean for CA19-9 values was $20.9 \mathrm{U} / \mathrm{ml}, 21.0 \mathrm{U} / \mathrm{ml}, 8.3 \mathrm{U} / \mathrm{ml}, 6.8 \mathrm{U} / \mathrm{ml}, 6.3 \mathrm{U} / \mathrm{ml}, 5.5$ $\mathrm{U} / \mathrm{ml}$, below the detection limit, $1.2 \mathrm{U} / \mathrm{ml}$ and $1.0 \mathrm{U} / \mathrm{ml}$, respectively. The difference of the geometric mean values between the children and the parents was statistically significant $(p<0.0001$, ANOVA adjusted for sex $)$ (Table 3 and Figure 2).
Effects of height, weight, and BMI on serum CA19-9 among the children

Among those with Le/Le or Le/le (the subjects excluding those with $l e / l e)$, it was found that children aged less than 20 years with high BMI $\left(20 \mathrm{~kg} / \mathrm{m}^{2}\right.$ and more $)$ indicated lower values of serum CA19-9 ( $p=0.007$, ANOVA adjusted for age groups, sex and $\mathrm{Se}$ genotype) (Table 4). Among the same subjects, the regression analysis indicated that logarithm of CA19-9 was significantly
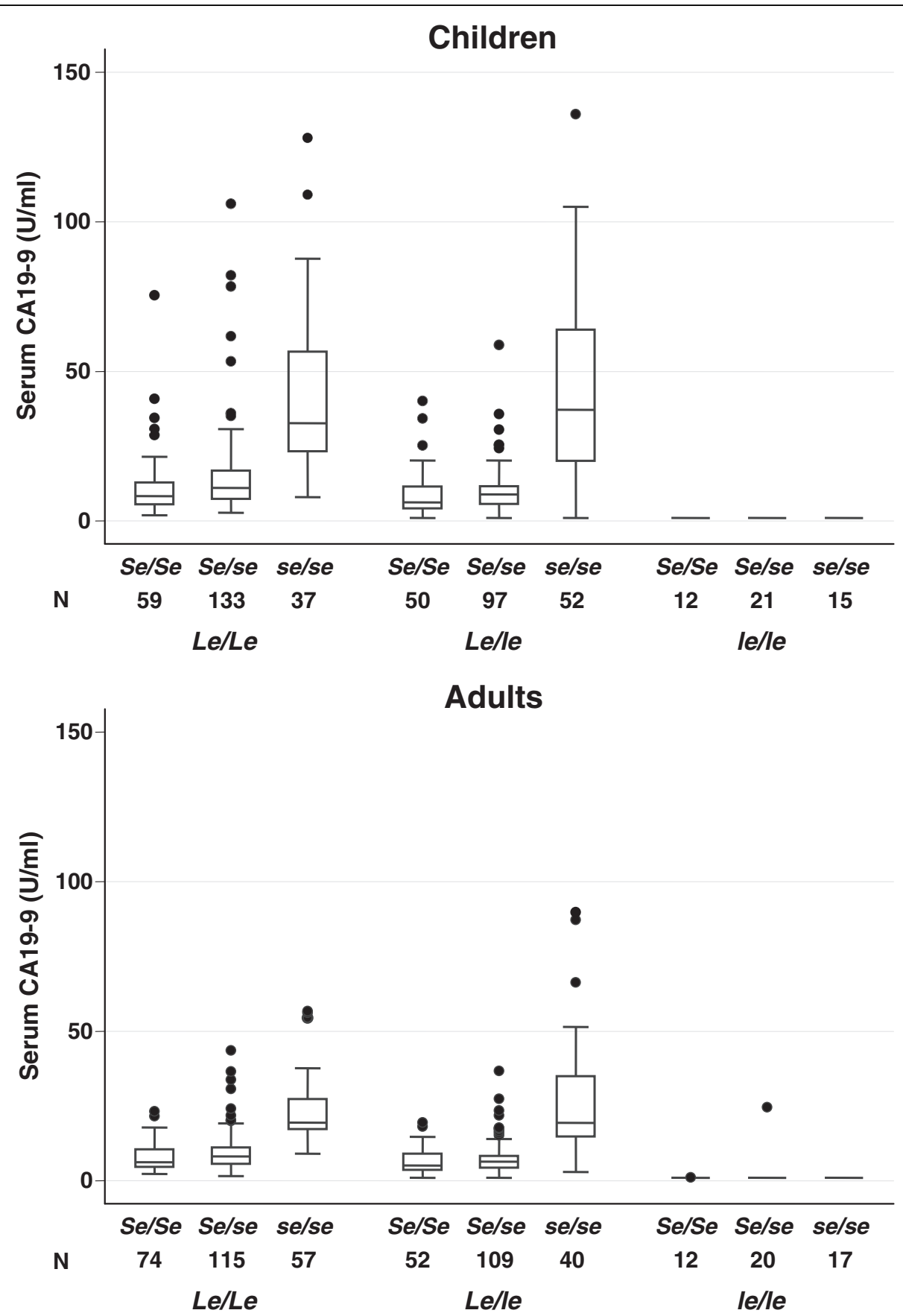

Figure 2 Distribution of serum CA19-9 according to Le and Se genotypes. 
Table 4 Geometric means of serum CA19-9 for body mass index (BMI) among the children excluding those with le/ le genotype

\begin{tabular}{ccccc}
\hline & $\mathbf{N}$ & Geometric mean $(\mathbf{U} / \mathrm{ml})$ & $\boldsymbol{F}^{*}$ & $\boldsymbol{p}$-value \\
\hline BMl $\left(\mathrm{kg} / \mathrm{m}^{2}\right)<20$ & 275 & 13.6 & & \\
$\mathrm{BMI}\left(\mathrm{kg} / \mathrm{m}^{2}\right) \geq 20$ & 153 & 9.6 & 7.31 & 0.007 \\
\hline
\end{tabular}

"Calculated by ANOVA adjusted for age group, sex and Se genotype.

associated with any of BMI $(\beta,-0.018, p<0.001)$, height $(\beta,-0.005, p<0.001)$ and weight $(\beta,-0.006, p<0.001)$ adjusted for sex and $S e$ genotype, while the associations were not observed among their parents $(p=0.31$ for BMI, $p=0.17$ for height, and $p=0.71$ for weight). The associations among the children were still significant when they further adjusted for age ( $p=0.022$ for BMI, $p=0.013$ for height, and $p=0.002$ for weight) (Table 5).

\section{Discussion}

There were few reports on serum CA19-9 values of children. Except for the case-control studies with a limited number of controls, this is the first report of the distribution of serum CA19-9 values of subjects aged less than 20 years. The new finding is that the children in early years indicated high serum CA19-9 values and it decreases along with their maturation.

Since $\mathrm{Le}$ and $\mathrm{Se}$ genotypes influence serum CA19-9 levels, the genotypes were taken into account for the present study. The allele frequencies were similar to those of the previous studies for Japanese population $[10,18]$. In $L e$ gene, le/le genotype has no enzyme activity, which results in no synthesis of CA19-9 even among cancer patients. In Se gene, 385T ( $e j$ ) and pseudogene

Table 5 Coefficients ( $\beta$ ) of BMI, height and weight, estimated by regression analysis for the logarithm of CA19-9 among the subjects excluding those with le/le genotype

\begin{tabular}{|c|c|c|}
\hline & $\beta$ (p-value) & $\beta$ ( $p$-value) \\
\hline & $\begin{array}{l}\text { adjusted for sex \& Se } \\
\text { genotype }\end{array}$ & $\begin{array}{c}\text { adjusted for sex, Se genotype } \\
\qquad \& \mathrm{age}^{\mathrm{a}}\end{array}$ \\
\hline \multicolumn{3}{|l|}{ Children } \\
\hline BMI & $-0.018(<0.001)$ & $-0.010(0.022)$ \\
\hline Height & $-0.005(<0.001)$ & $-0.003(0.013)$ \\
\hline Weight & $-0.006(<0.001)$ & $-0.005(0.002)$ \\
\hline \multicolumn{3}{|l|}{ Parents $^{b}$} \\
\hline BMI & $0.004(0.31)$ & $0.003(0.39)$ \\
\hline Height & $-0.003(0.17)$ & $-0.002(0.25)$ \\
\hline Weight & $0.001(0.71)$ & $0.001(0.70)$ \\
\hline
\end{tabular}

${ }^{\mathrm{a}}$ Five-year age groups.

${ }^{\mathrm{b}}$ Drinking and smoking statuses are added as adjusting factors. (se5) are no activity alleles, so that $s e j / s e j, s e j / s e 5$, and se5/se5 genotypes are concerned with over synthesis of CA19-9. This study reported $L e$ and Se genotype frequencies and the geometric mean values of serum CA19-9 for each combination of these genotypes. The combination of the full enzyme activity genotype of $L e$ gene ( $L e / L e$ or Le/le) and no enzyme activity genotype of $\mathrm{Se}$ gene $(\mathrm{se} / \mathrm{se}$ ) indicated the highest mean value of serum CA19-9 among both of the generations.

In case of Caucasians, although the reported polymorphisms of $L e$ and $\mathrm{Se}$ genes are partly different from Japanese, the alleles without enzyme activity are observed. The common haplotypes without enzyme activity are 59G \& 508A (le1) and 59G \& 1067A (le2) in Japanese, and $59 G$ \& $314 T$ in Caucasians [19]. Any of 508A, 1067A and 314T alleles of Le gene could lead to lose the Lewis enzyme activity. Concerning $\mathrm{Se}$ gene, common alleles without enzyme activity are $s e j$ and $s e 5$ among Japanese, and $428 \mathrm{~A}$ of G428A polymorphism in Caucasians. Although there was no previous information about the frequencies of $\mathrm{Le}$, Se genotypes among Japanese-Brazilians, their genetic background is basically the same and this study showed the similar frequencies to the previous Japanese population. Since there are no substantial differences in frequency of no activity alleles between Caucasians and Japanese, the consequence of this study would be applicable to any population groups.

The present study showed that serum CA19-9 levels were significantly higher in children than in their parents, and it seemed to be associated with body constitutions or maturity. The mean serum CA19-9 value of the parents of children whose CA19-9 values were higher than $37 \mathrm{U} / \mathrm{ml}$ was $12.3 \mathrm{U} / \mathrm{ml}$ and those of the rest of parents was $10.4 \mathrm{U} / \mathrm{ml}$; the difference was not statistically significant $(p=0.19$, ANOVA adjusted for age groups, sex and $L e$ and Se genotypes). In this study, the youngest group indicated the highest mean value of serum CA19-9 in five-year age groups of the children. The regression analysis showed that younger age and high serum CA19-9 level were significantly associated among the children $(p<0.001)$. This result was inconsistent with the study in Finland about 20 years ago, which was concluded that the age of individuals did not have any influence on the concentrations of the CA19-9 marker [12]. However, they also reported that the range of serum CA19-9 levels in healthy children were clearly wider than in adults and there were no detailed information about the mean values of each age groups.

At the beginning, we thought the feasible candidate for explaining the association between younger age and high serum CA19-9 was BMI. ANOVA demonstrated that children with high BMI $\left(20 \mathrm{~kg} / \mathrm{m}^{2}\right.$ and more $)$ indicated significantly lower values of serum CA19-9 $(p=0.007)$. Then we conducted the regression analysis 
with BMI, as well as height and weight, to test the hypothesis that the tendency could be associated with body constitutions. Any association with BMI, height and weight was significant, and the associations were still significant when they adjusted for age. Therefore, BMI seems to be one of the factors to determine the serum CA19-9 levels independently of ageing. Recently, one study reported that obese men had lower tumor marker levels, including CA19-9, than men in normal weight. They considered that hemodilution from increased plasma volume was the main reason of the observed decrease in tumor marker concentration in men with a high BMI [20]. However, decreasing of serum CA19-9 was not the results for obese among the present study subjects, there could be other unknown factors we should focus on.

\section{Conclusions}

Serum CA19-9 values were higher among children than among adults, and influenced by sex, height, weight, and BMI even after the adjustment for age as well as Le and $\mathrm{Se}$ genotypes. Further investigation would be required to elucidate the mechanism of this phenomenon.

\section{Abbreviations}

BMI: Body mass index; CIEIA: Competitive inhibition enzyme immunoassay; PCR-CTPP: Polymerase chain reaction with confronting two-pair primers; Le gene: Lewis gene; Se gene: Secretor gene; ANOVA: Analysis of variances.

\section{Competing interests}

The authors have no conflicts of interest and did not receive any outside assistance writing this manuscript.

\section{Authors' contributions}

SK performed the statistical analysis and drafted the manuscript. SMO, LSI, MU, and SKNM have made substantial contributions to study design, acquisition of data, and manuscript preparation. $\mathrm{NH}$ conceived of the study. All authors read and approved the final manuscript.

\section{Acknowledgements}

This study was supported in part by a Grant-in-Aid for Scientific Research on Special Priority Areas of Cancer from the Japanese Ministry of Education, Culture, Sports, Science, and Technology. We are grateful to Ms. Yoko Mitsuda and Ms. Keiko Shibata for their technical assistance.

\section{Author details}

'Department of Preventive Medicine, Nagoya University Graduate School of Medicine, 65 Tsurumai-cho, Showa-ku, Nagoya, Japan. ' Laboratory of Molecular and Cellular Biology, Department of Neurology, School of Medicine, University of São Paulo, São Paulo, Brazil. ${ }^{3}$ Japanese Brazilian Health Professional Volunteer Group, São Paulo, Brazil.

Received: 1 May 2012 Accepted: 29 November 2012 Published: 04 December 2012

\section{References}

1. Herlyn M, Sears HF, Steplewski Z, Koprowski H: Monoclonal antibody detection of a circulating tumor-associated antigen. I. Presence of antigen in sera of patients with colorectal, gastric, and pancreatic carcinoma. J Clin Immunol 1982, 2:135-40.

2. Farini R, Fabris C, Bonvicini P, Piccoli A, del Favero G, Venturini R, Panucci $A$, Naccarato R: CA 19-9 in the differential diagnosis between pancreatic cancer and chronic pancreatitis. Eur J Cancer Clin Oncol 1985, 21:429-32.
3. Harder J, Kummer O, Olschewski M, Otto F, Blum HE, Opitz O: Prognostic relevance of carbohydrate antigen 19-9 levels in patients with advanced biliary tract cancer. Cancer Epidemiol Biomarkers Prev 2007, 16:2097-100.

4. Patel $A H$, Harnois DM, Klee GG, LaRusso NF, Gores GJ: The utility of CA 19-9 in the diagnoses of cholangiocarcinoma in patients without primary sclerosing cholangitis. Am J Gastroenterol 2000, 95:204-7.

5. Engelen MJ, de Bruijn HW, Hollema H, ten Hoor KA, Willemse PH, Aalders $J G$, van der Zee AG, Serum CA: 125, carcinoembryonic antigen, and CA 19-9 as tumor markers in borderline ovarian tumors. Gynecol Oncol 2000, 78:16-20.

6. Shudo R, Saito T, Takahashi K, Horita K, Waku K, Honma I, Sato T: Giant hydronephrosis due to a ureteral stone, and elevated serum levels of CA 19-9. Inter Med 1999, 38:887-91.

7. Parra JL, Kaplan S, Barkin JS: Elevated CA 19-9 caused by Hashimoto's thyroiditis: review of the benign causes of increased CA 19-9 level. Dig Dis Sci 2005, 50:694-695.

8. Magnani JL, Nilsson B, Brockhaus M, Zopf D, Steplewski Z, Koprowski H, Ginsburg V: A monoclonal antibody-defined antigen associated with astrointestinal cancer is a ganglioside containing sialylated lacto-Nfucopentaose II. J Biol Chem 1982, 257:14365-9.

9. Vestergaard EM, Hein HO, Meyer H, Grunnet N, Jørgensen J, Wolf H, Orntoft TF: Reference values and biological variation for tumor marker CA 19-9 in serum for different Lewis and secretor genotypes and evaluation of secretor and Lewis genotyping in a Caucasian population. Clin Chem 1999, 45:54-61.

10. Narimatsu H, Iwasaki H, Nakayama F, Ikehara Y, Kudo T, Nishihara S, Sugano K, Okura H, Fujita S, Hirohashi S: Lewis and secretor gene dosages affect CA19-9 and DU-PAN-2 serum levels in normal individuals and colorectal cancer patients. Cancer Res 1998, 58:512-8.

11. Kawai S, Suzuki K, Nishio K, Ishida Y, Okada R, Goto Y, Naito M, Wakai K, Ito $Y$, Hamajima N: Smoking and serum CA19-9 levels according to Lewis and secretor genotypes. Int J Cancer 2008, 123:2880-4.

12. Heikinheimo M, Rajantie J, Kuusela P, Kallio MJ, Siimes MA: Oncofetal markers CA 19-9, CA 125 and SP1 in healthy children and in children with malignancy. Br J Cancer 1990, 62:865-7.

13. Kajiume T, Yoshimi S, Kobayashi K, Kataoka N: A case of malignant lymphoma in a patient with high levels of CA125 and CA19-9. Pediatr Hematol Oncol 2000, 17:269-72.

14. Kajbafzadeh AM, Elmi A, Talab SS, Emami H, Esfahani SA, Saeedi P: Urinary and serum carbohydrate antigen 19-9 as a biomarker in ureteropelvic junction obstruction in children. J Urol 2010, 183:2353-60.

15. Ito LS, Oba-Shinjo SM, Shinjo SK, Uno M, Marie SK, Hamajima N: Community-based familial study of Helicobacter pylori infection among healthy Japanese Brazilians. Community-based familial study of Helicobacter pylori infection among healthy Japanese Brazilians. Gastric Cancer 2006, 9:208-16.

16. Hamajima N, Saito T, Matsuo K, Kozaki K, Takahashi T, Tajima K: Polymerase chain reaction with confronting two-pair primers for polymorphism genotyping. Jpn J Cancer Res 2000, 91:865-8.

17. Oba-Shinjo SM, Uno M, Ito LS, Shinjo SK, Marie SK, Hamajima N: Association of Lewis and Secretor gene polymorphisms and Helicobacter pylori seropositivity among Japanese-Brazilians. J Gastroenterol 2004, 39:717-23.

18. Elmgren A, Börjeson C, Svensson L, Rydberg L, Larson G: DNA sequencing and screening for point mutations in the human Lewis (FUT3) gene enables molecular genotyping of the human Lewis blood group system. Vox Sang 1996, 70:97-103.

19. Ørntoft TF, Vestergaard EM, Holmes E, Jakobsen JS, Grunnet N, Mortensen M, Johnson P, Bross P, Gregersen N, Skorstengaard K, Jensen UB, Bolund L, et al: Influence of Lewis alpha1-3/4-L-fucosyltransferase (FUT3) gene mutations on enzyme activity, erythrocyte phenotyping, and circulating tumor marker sialyl-Lewis a levels. J Biol Chem 1996, 271:32260-8.

20. Chang $I_{H}$, Ahn SH, Han JH, Kim TH, Kim YS, Myung SC: The clinical significance in healthy men of the association between obesity related plasma hemodilution and tumor marker concentration. J Urology 2009, 181:567-72.

doi:10.1186/1472-6890-12-23

Cite this article as: Kawai et al:: Factors associated with serum CA19-9

levels among healthy children: a cross-sectional study. BMC Clinical Pathology 2012 12:23. 